\title{
Milk Consumption and Chronic Disease Risk - The Strategy or Challenge to Avoid and Eliminate "Unwanted" Compounds and Contaminants
}

\author{
Gordana M. Kocic ${ }^{1}$, Tatjana Jevtovic-Stoimenov ${ }^{1}$, Dusan Sokolovic ${ }^{1} \&$ Hristina Kocic $^{2}$ \\ ${ }^{1}$ University Nis, Medical Faculty, Nis, Serbia \\ ${ }^{2}$ University Maribor, Medical Faculty, Maribor, Slovenia \\ Correspondence: Gordana Kocic, University Nis, Medical Faculty, Nis, Serbia. Tel: 381-63-812-2522. E-mail: \\ kocicrg@yahoo.co.uk
}

Received: February 12, 2015 Accepted: March 14, 2015 Online Published: April 15, 2015

doi:10.5539/jas.v7n5p154 URL: http://dx.doi.org/10.5539/jas.v7n5p154

\begin{abstract}
Milk consumption is a subject of many opposing opinions, regarding its epigenetic influence on genomic and proteomic cell events, what may change inflammatory, metabolic, oxidative and neurocognitive function. For some of milk ingredients, such as saturated lipids, lactose and some casein forms, the pathogenetic mechanisms were documented. Certain products, including some enzymes, low-weight partially digested peptides and non-protein nitrogen compounds, are still in the serious observations. To avoid ,unwanted“ compounds is complex, because of different conditions of their appearance, what in some extent determines if they can be avoided in pre-dairy manufacturing or eliminated in a dairy manufacturing and post-dairy processing and packing. Pre-dairy manufacturing should represent new approaches toward genetic selections of dairy breeds regarding milk biochemical composition ( $\beta$-caseins). A number of contaminants, from pesticides to drugs, toxins, hormones, heavy metals, pharmaceuticals, phthalates, carcinogens, synthetic chemicals, or veterinary drugs may appear in a pre-dairy process through the plant material (forage) or artificially via (uncontrolled) cattle treatment. A proper growing and planting conditions, antifungal chemical treatment or dry collection of feedstuffs, or destruction of mycotoxins by biodegradation process may decrease their content. Unwanted compounds of milk, which may be eliminated during dairy manufacturing and packing, may be xanthine oxidase, uric acid, saturated fats and lactose. Beside low fat milk production, the quality improvement in milk fatty acids composition can be achieved by changing the animal feeding type. Regarding lactose or its components, glucose and galactose, it should be clearly distinguished the sugar-free milk from milk containing digested lactose, on the pack nutrition label. The main contaminants which appear, because of dairy products packing in plastic bottles and cups, are phthalates. Good agricultural practices (GAPs) concerning dairy industry should be directed to integrate different preventive strategies and to satisfy personalized nutrition concept.
\end{abstract}

Keywords: milk, xanthine oxidase, uric acid, $\beta$-casein type A1, lactose, phtalates

\section{Introduction}

In recent years the nutrigenomics tried to search for dietary factors which may contribute to development of various (the most common) chronic diseases, such as atherosclerosis, cardiovascular events, diabetes, chronic inflammatory conditions, autoimmune disorders, allergies and malignancies, by making the integration of genomic science and nutrition (Simopoulos, 2010). Regarding above mentioned diseases, milk consumption has become a subject of different, often opposing opinions, regarding its effect on inflammatory, metabolic, oxidative and neuro-cognitive function (Mead, 2007). Among the certain things are that milk and dairy products represent the best providers of calcium, other minerals, vitamins and essential amino acids (Figure 1). 


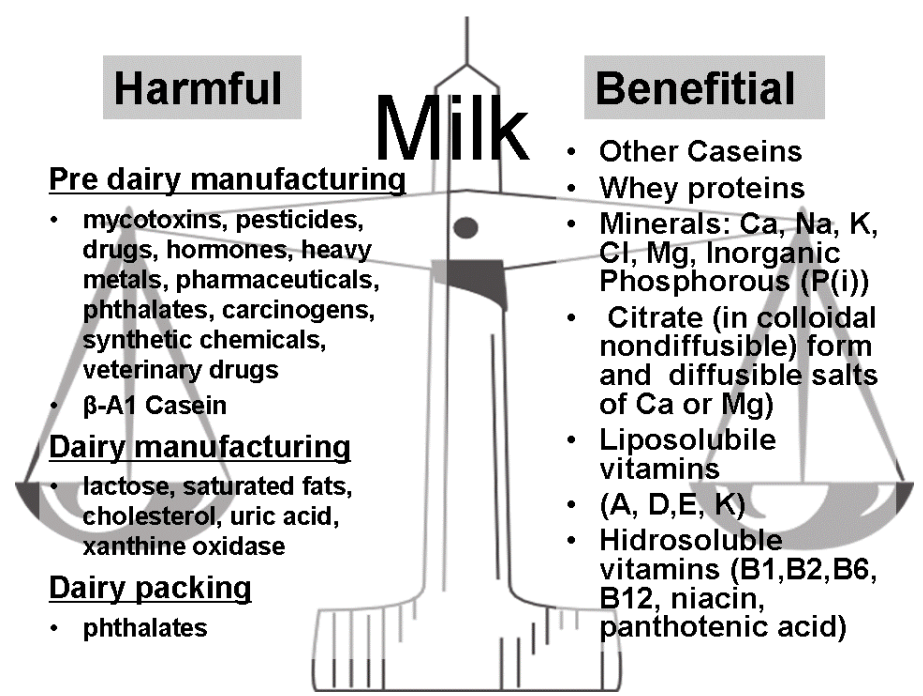

Figure 1. Beneficial and possible harmful milk ingredients and contaminants

The ingredients that may contribute to atherogenic potential of milk are different. For some of them, such as saturated lipids, lactose and some casein forms, the mechanisms of atherogenic effect were documented (Laugesen et al., 2003; Segall, 1994, 2002; Warensjo et al., 2010; Markey et al., 2014). Other ingredients or products, like some enzymes, low-weight partially digested peptides and non-protein nitrogen compounds, are still in the serious observations, as it was published by Awasthi et al. (2012), and Kocic et al. (2014). To avoid "unwanted" compounds is complex, because of different conditions of their appearance, what in some extent determines if they may be avoided in pre-dairy manufacturing or eliminated in a dairy manufacturing and packing.

\section{Unwanted Compounds Which Could Be Avoided during Pre-Dairy Manufacturing}

Pre-dairy manufacturing should represent new approaches toward genetic selections of dairy breeds not only regarding higher milk production, but regarding milk biochemical composition. Beside this, an adequate nutrition program should be directed to avoid any unwanted toxic substances.

\section{$2.1 \beta$-Casein Type A1}

Caseins are the main protein components in cows' milk (consisting about $80 \%$ of milk proteins) representing the major source of essential amino acids. Casein is a complex protein, belonging to phosphoproteins and three major groups ( $\alpha \mathrm{S} 1, \alpha \mathrm{S} 2, \beta$, and $\kappa$ casein) have been identified. They are present in specific milk micellar structures (Elliot et al., 1999). Experimental $\beta$-casein type A feeding may lead to increased level of homocysteine, which is a documented risk factor for atherosclerosis and to increased oxo-LDL (Laugesen \& Elliot, 2003). Significant number of publications pointed out a causal link between $\beta$-casein type A1 and development of Type 1 diabetes, since the enhanced levels of antibodies to $\beta$-casein in children with Type 1 diabetes were obtained. Partial digestion of $\beta$-casein type $\mathrm{A} 1$ by digestive tract proteolytic enzymes can produce casomorphins, a family of small peptides with potent immune and opioid activity. Up to now, about 30 opioid peptides were isolated from milk, such as types of casomorphins 4, 5, 6, 7, 8, 9, 11, 13, 21, all of them isolated from bovine $\beta$-casein. Only two types of opioid bioactive peptides, known as exorphins, were isolated from $\alpha$-casein (Kostyra et al., 2004). The types 7 and 8 were isolated from human milk as well. Their opioid activity increases with their hydrophobicity, due to higher hydrophobic interaction and affinity to opioid receptors, similar to morphine affinity. The appearance of Type 1 diabetes may be immunologically linked to the homology between the amino acid sequence of $\beta$-casomorphin 7 (BCM7) and the pancreatic glucose transporting molecule GLUT2. The symptoms of autism and schizophrenia, other auto-immune conditions and milk intolerance are also linked to $\beta$-casein-A1. Regarding the A types of caseins, the difference between bovine A1 and A2 $\beta$-casein is only one amino acid of 209 , since A2 $\beta$-casein has a proline at position 67 , while A1 $\beta$-casein has a histidine. Most probably this point mutation occurred several thousand years ago. The histidine at position 67 in A1 $\beta$-casein accelerated partial casein digestion, with the subsequent release of the opioid peptide BCM7, which can easily cross the blood brain barrier. It might probably lead to neuropsychiatric behavior patterns, observed in autism and schizophrenia (Meisel \& FitzGerald, 2000). The opinion that genetically $\beta$-casein A1 phenotypes are responsible for the "wrong milk" points out practical genomics to careful phenotyping for $\mathrm{A} 1 / \mathrm{A} 2$ status and subsequent $\mathrm{A} 2$ cattle selection. 


\subsection{Pre-Dairy Chemical Contaminants, Drugs and Toxins}

A number of contaminants, from pesticides to drugs, toxins, hormones, heavy metals, pharmaceuticals, phthalates, carcinogens, synthetic chemicals, or veterinary drugs may appear in a pre-dairy process through the plant material (forage) or artificially via (uncontrolled) cattle treatment by the accidental feeding and further transmission of contaminants or its possible metabolite into the milk of dairy cattle.

The plant toxin goitrin (5-viniloksazolidin-2-thione) exerts toxic effects on the thyroid gland, considered to be strumogenic. Toxins belonging the group of pyrrolizidines are present in Senecio plants jacobea (Bachmann et al., 1985).

The mycotoxins, especially aflatoxins (AF), are experimentally documented to act as the strong hepatotoxicants, which may induce liver and kidney cancer, teratogenicity and mutagenicity. The hazard ratio increases with the fact that the pasteurization and sterilization conditions are not able to destroy these toxins, which were documented to be heat resistant. Up to now several AF chemical forms and metabolites were documented to exist, such as $\mathrm{B} 1, \mathrm{~B} 2, \mathrm{G} 1, \mathrm{G} 2$ and M. Metabolism of AF in liver is very complex and may occur in different ways, such as hydroxylation, epoxydation, hydratation or demethylation. Each of these steps mainly depends on catalytic action of liver corresponding microsomal enzymes, among which of essential importance belongs to cytochrome P450. Aflatoxicol appears as a secondary metabolite of Aflatoxin B1 (AFB1) after its reduction by the digestive tract flora. The appearance of aflatoxin $\mathrm{M}_{1}$ in milk of cattle, sheep and goats corresponds to the ingested aflatoxin $\mathrm{B}_{1}$, representing a biomarker of $\mathrm{AF}$ exposure, inspite of the fact that only $1.5 \%$ of $\mathrm{AFB}_{1}$ can be excreted as the metabolite $\mathrm{AFM}_{1}$ (Kiermeier, 1973). Other AF metabolites like AFM2 and AFM4 are present in a very small, almost negligible amount. Metabolites of AF are highly reactive compounds, they can bind covalently to DNA, making DNA adducts, what may induce DNA mutation. The additional damaging effect may appear from oxidative damage of cells, because of reduced glutathione depletion. Excess of reactive oxygen species may also led to programmed cell death (apoptosis). Epoxidation (8, 9, AFB1 epoxide) is of greatest importance for AF carcinogenic or delayed mutagenic potential, because of its electrophylic attack to nitrogen or oxygen of purine bases (AFB1-N7 guanine adduct). At the same time, epoxide level directly correlates with reactive oxygen species (ROS) level. From carcinogenic point of view, the adduct formation may be of importance by inducing mutation of p53 suppressor gene (Elaton \& Gallanger, 2004). Main sources of mycotoxins are different feedstuffs, like forages, concentrates and preserved feeds, such as silage, hay, and straw (O'Brien, 2005). Aflatoxins may occur especially in energy-rich feedstuffs concentrates, such as the grains, corn, soybean, oil plants like sunflower seeds. Mycotoxins like fumonisins and zearalenone may be found in maize derived products, while trichothecenes and ergot alkaloids may be found in cereal grains (Nawaz et al., 1997). Ergovaline may be found in pasture grasses (Cheeke, 1995). After absorption they can be excreted into milk. Good agricultural practices (GAPs) is directed mainly toward different preventive strategies, such as proper growing and planting conditions, antifungal chemical treatment or dry collection of feedstuffs. As the new promising strategies are the approaches regarding possible destruction of mycotoxins by biodegradation process, using different microbes, like probiotic bacteria, enzymes, metals salts and surfactants (Salminen et al., 2010; Das et al., 2014).

Artificially present pesticides or heavy metals may appear in soils and plants as a result of use of agricultural chemicals, industrial pollutant or car exhaust. Heavy metals, like $\mathrm{Pb}, \mathrm{Cd}, \mathrm{Fe}, \mathrm{Hg}, \mathrm{Cu}$, represent persistent environmental hazard, causing a multi-organ failure, followed by many metabolic abnormalities, but followed also with the economic losses due to disease treatment costs (Bischoff et al., 2014). The pollution with $\mathrm{Pb}$ may occur by industrial processes emissions, like the traffic petrol, the smoke, but also because of the use of different paints. As a typical cumulative poison, it can be accumulated in bones and bone marrow, in the kidney and liver tissue, leading to the inhibition of hem synthesis and development of chronic anemia, encephalopathy, reproductive function failure. The carcinogenic and delayed mutagenic effects were also documented. The contamination of milk may be due to feeding of the cows with fodder collected near the big roads. Similar toxic effects can be diagnosed by Cd poisoning, with deposition and consequent damage of parenchimatous organs, like kidneys, liver, and lungs.

Pesticides represent the most persistent pollutants in the environment, ingested through water or forages, causing contamination of milk. Among pesticides, most often are the lypophilic chemicals, exerting very high affinity to bind to lipid structures they can be easily accumulated in different tissue lipoprotein structures. Such types are chlorinated pesticides, organophosphates, herbicides, fungicides and anti-helmintic chemicals. They can cause a number of systemic toxic effects, such as anemia, reproductive failure, parenchimatous organs damage (liver and kidney) or brain damage. Some lactic acid bacteria may be useful in their degradation (Villarroel et al., 2013; Witczak et al., 2013; Zhou et al., 2015). 
Antibiotics and sulphonamides can be present in cow milk as veterinary agents, after treatment of mastitis. Phthalates, phenolic compounds, detergents and desinfectants and their metabolites may usually get into water as a result of use of pharmaceuticals, agricultural chemicals, households chemicals or from industrial wastes (Khaniki, 2007; Awasthi et al., 2012).

An increasing focus on prevention of the pollution by radioactive compounds should be emphasized as well, because of possible local nuclear accidental catastrophes or other possible ways of contamination during war conditions. Among radioactive elements, the concentrations of radioactive cesium (134 and 137) Cs, iodine and uranium may be detected in dairy products from contaminated regions (Miyazaki et al., 2013; Belles et al., 2013).

All of the above mentioned unwanted compounds may be detected during milk collection and can be avoided before the dairy manufacturing process by high quality control.

\section{Unwanted Compounds Which Could Be Eliminated during Dairy Manufacturing and Packing}

\subsection{Milk Homogenization, Xanthine Oxidase Liberation and Urate Level}

Commercial liquid milk is commonly homogenized. Fresh, unprocessed milk contains different purine and pyrimidine compounds mainly as adenine and guanine ribonucleotides or free bases (hypoxanthine and xanthine). Purine ribonucleotides which are usually present in milk, can be degraded to uric acid by milk fat globule xanthine oxidase, during the dairy process of milk homogenization (Harrison, 2002; Harrison, 2006; Michalski, 2007). Milk fat globules are secreted after synthesis in the endoplasmic reticulum of the mammary gland. Since xanthine oxidase is located in the milk fat globule in its inactive form, procedures of homogenization of milk induces its liberation from fatty globules, what is also followed by a subsequent activation. Xanthine oxidase may also be activated during milk intestinal digestion (Harrison, 2002). In the above reactions, a strong free radical, superoxide anion is liberated. The activity of xanthine oxidase in breast milk seems to be beneficial in the newborn period, as a major bactericidal element for the prevention of gut infection (Stevens et al., 2000). But in a later age, the activity of xanthine oxidase may be harmful because of its prooxidative function. A hypothesis about possible atherogenic effect of xanthine oxidase proposed that XO after its gastrointestinal absorption may across into the bloodstream, where it can damage endothelium by binding, immune reactivity and in situ free radical production (Harrison, 2002). Since enzymes, as protein structures, can be inactivated (denaturated) by using high temperature, the UHT sterilization would be the most suitable way of its inactivation.

Regarding the presence of uric acid in milk, its possible harmfull effects were documented in primary hyperuricemia (gout, urate nephrolithiasis, Lech-Nychan syndrome), secondary hyperuricemia (preeclampsia, cardiovascular diseases, hypertension, diabetes mellitus, stroke, dementia, obesity, alcohol abuse, tumor lysis syndrome, AIDS, psoriasis, high sport demands, age over 65 and "stress manager disease") (Sculley et al., 1992; Dincer et al., 2002; Iseki et al., 2004; Schretlen et al., 2007; Tatli et al., 2008; Gonzalez et al., 2008). High uric acid in blood may increase several times cardiovascular risk or stroke and can enhance oxidation of LDL lipoproteins (Feig et al., 2008). Hyperuricemia may be linked to disorders in cognitive functioning and in dementia (Schretlen et al., 2007). In order to satisfy the demand of healthy dairy product for population under hyperuricemic risk, we produced milk almost free of purine and uric acid. Our experimental studies documented positive impact of depurinized milk on liver regenerative signaling transduction pathway, anti-apoptotic signaling, myocardial reparation, antioxidative potential and bone-marrow stem cell potential (Kocic et al., 2014a, 2014b). Urate crystals can induce immuno-inflammatory effect acting as the damage-associated mollecular patterns (DAMP), after binding to the surface of antigen-presenting cells, what induces strong IL-1 $\beta$ production (Foell et al., 2007; Cheng et al., 2008). Uric acid can induce mechanical endothelial damage, vascular remodeling, smooth muscle cell proliferation and endothelial dysfunction, can increase platelet adhesiveness and aggregability, and can stimulate neutrophils adhesion. Urate crystals were detected inside of the atherosclerotic plaques (Feig et al., 2008). Urates can aggravate eclamptic pregnancy, by inducing inflammation, endothelial dysfunction, hypertension, they may damage placenta, affecting in this way intrauterine growth (Bainbridge \& Roberts, 2008). Since the linear correlation between the uric acid level and the appearance of symptoms of cardiovascular or renal dysfunction was not documented, it would be recommended to avoid uric acid or their source (purines) of food especially in older age (Dincer et al., 2002). In order to satisfy the demand of healthy dairy product for population prone to uric acid unwanted effects, we produced "depurinized" milk almost free of purine nucleotides and uric acid (Kocic et al., 2014a, 2014b).

\subsection{Milk Fats}

The milk as a source of the milk fat in an amount of 3-4\%, can significantly contribute to the general nutritional input of lipids. Milk fat is composed of neutral lipids (primarily triglycerides) and polar lipids, structured as emulsified milk fat globules (MFG), finely dispersed as very small (5-10 microns in diameter) drops in the water 
phase. The fatty acids involved in composing milk triglycerides are very different in carbon size (from 4 to 26 carbons), mainly saturated (about two thirds), branched and linear, regarding the structure of carbon chain. About $12 \%$ of the fatty acids are short-chain, such as butyric, caproic, caprylic, capric acids, conjugated linolenic acid, sphingolipids and fat soluble vitamins (A, D, E and K). Regarding the milk fat involvement in atherogenic blood lipid profile with high LDL lipoprotein content, associated with cardiovascular risk, the main contribution belongs to saturated fatty acids, the level of which exceeds $60 \%$ in milk. The most hazardous of them are C12, C14 and C16 chain saturated milk fatty acids. Others, like short-chain fatty acids, polyunsaturated fatty acids or branched fatty acids have been documented to possess bioactive properties, having influence on gene expression, exerting hormone-like, anticancerogenic and antimicrobial activity and may decrease cardiovascular risk through the decrease of LDL cholesterol level (Parodi, 2004).

The effect of milk fats on human health may be considered to be favorable to human health, compared to other animal fat sources, but unfavorable, compared to low or fat-free milk. That is why the dairy industry has in recent years worked intensively on manufacturing the low-fat, fat-modified or fat-free milk, what involved filtering out the fat from the milk or supplementation of polyunsaturated fatty acids (Markey et al., 2014; Ferreiro et al., 2015). Above mentioned articles may suggest that low-SFA or fat-modified milk should be preferred, regarding cardio-metabolic benefit, when compared to commercially available whole milk dairy products. In the newest meta analysis a total of 22 studies were analyzed regarding the role of low-fat dairy products in preventing cardiovascular diseases. Above mentioned meta analysis supported this finding (Qin et al., 2015). The low-fat milk can be protective against development of type 2 Diabetes Mellitus through moderate insulin sensitizing effect, as recent meta analysis has been documented (Abedini et al., 2015). Beside low fat milk recommendation, the quality improvement in milk fatty acids composition can be achieved by changing the animal feeding type (organically managed cows) by supplementation of polyunsaturated fatty acids, short-changed fatty acids, antioxidants, vitamins A, E, and trace element Selenium (Martemucci \& D'Alessandro, 2013; Ferreiro et al., 2015).

\subsection{Lactose}

Lactose represents a normal constituent and the most important sugar in milk. The Scientific Committee recommendations for nutrition and food standards agencies admitted lactose as an atherogenic factor of diet. Well known 'French paradox', regarding the unexplained lower cardiovascular mortality may be explained, beside other factors, by increased prevalence of lactose intolerance and cheese (low lactose) supply more than milk drinking. Insulin resistance syndrome that was almost commonly seen in some African blacks and Pima Indians may be linked with high appearance of lactose intolerance and low milk intake. If milk lactose may be risk factor for the development of atherosclerosis depends mainly on the activity of intestinal lactase, which catalyzes its degradation to glucose and galactose. With regard to chemical properties and affinity to carriers, galactose is reabsorbed from the intestines by using the same carrier (specific for the position of the hydroxyl group on carbon two) as glucose, and then, under physiological conditions it undergoes mainly to specific galactokinase-dependent metabolic pathway. Congenital disorder of galactose metabolism leads to cataracts as a result the osmotic activity of galactose, which after entering the cells, can be converted into galactitol. A number of experimental data about the toxicity of galactose initiated clinical observations related to its cardiovascular risk (Segall, 1994, 2002). Galactose possesses higher affinity for nucleophilic attack and protein nonenzymatic galactosylation than glucose for glycation. Some experimental results documented that cell proteins can be galactosylated about 4-fold faster and more extensively, than glycosylated, compared under equimolar incubation conditions. Insulin makes more effective entry of galactose in a cell than the entry of glucose, contributing to the retention of glucose and development of insulin resistance or other long-term complications (Segall, 2002). Because of that, it is particularly important to distinguish milk types indicated as "lactose-free milk". It should be clarified if it really represents a sugar-free milk, or milk containing digested lactose to their monosaccharides, glucose and galactose. It can be identified clearly on the label packaging, but customers are supposed to know to interpret the packaging. For lactose intolerant (insufficient in lactase) young people, the milk containing digested lactose to glucose and galactose is suitable. If a person suffering from diabetes consumes the milk containing digested lactose, a chance to "better" absorbance of mentioned monosaccharides became higher. Proposed methods of chromatografic adsorption of lactose, proposed by Harju (2007) are now in use by some dairy manufacturers, but new challenges might be to the use of non-toxic natural lectins, according to experimental data of their properties.

\subsection{Contaminants of Milk Packing}

During the post-processing period, the dairy products may aquire potentially toxic substances as well. Phthalates, as unwanted lipophilic toxic compounds (plasticizers), are usually added to PVC for softening (Sorensen, 2006). They may appear in milk as a result of migration from plastic packaging. Exposure to phthalates may be linked to lungs, liver, kidneys injury and cancer development, increased blood pressure and endocrine system alteration 
(endocrine-disrupting chemicals-EDCs), accompanied with reduced male fertility. One way to reduce phthalate exposure includes avoiding products made of PVC plastics ("phthalate-free" on packaging), by choosing natural packing materials. In our study by using commercial $1.5 \%$ fat UHT cow milk, we isolated about 36 potentially toxic volatile chemically different aliphatic and aromatic aldehydes, ketones, carboxilic acids, sulphur compounds and six phthalate types. Technological procedure by using our device system was able to eliminate (adsorb) more than $90 \%$ of identified phthalates, supporting technology innovation in the dairy processing (Kocic et al., 2014a).

\section{Conclusion}

In conclusion, some milk ingredients or contaminants may directly affect human health, by having the influence on genomic, proteomic and metabolomic events, and these in turn may lead to disease initiation, development, or progression. Good agricultural practices (GAPs) concerning dairy industry should be directed to integrate different preventive strategies to ensure each stage of dairy processing. Since each body may respond differently to the same dairy product, the dairy industry may be supposed to produce different milk types, to satisfy personalized nutrition concept.

\section{Acknowledgements}

The study was supported by Ministry of Education and Science Republic Serbia project TR31060.

\section{References}

Abedini, M., Falahi, E., \& Roosta, S. (2015). Dairy product consumption and the metabolic syndrome. Diabetes Metab. Syndr., 9(1), 34-37. http://dx.doi.org/10.1016/j.dsx.2014.04.027

Awasthi, V., Bahman, S., Thakur, L. K., Singh, S. K., Dua, A., \& Ganguly, S. (2012). Contaminants in milk and impact of heating: an assessment study. Indian $J$. of Public Health, 56(1), 95-99. http://dx.doi.org/10.4103/0019-557X.96985

Bachmann, M., Theus, R., Lüthy, J., \& Schlatter, C. (1985). The occurrence of goitrogenic substances in milk. 1. Release of goitrin in the milk of cows fed on rapeseed extract cakes. Z Lebensm Unters Forsch., 181(5), 375-378. http://dx.doi.org/10.1007/BF01027401

Bainbridge, S, A., \& Roberts, J. M. (2008). Uric Acid as a Pathogenic Factor in Preeclampsia. Placenta, 29(Suppl. 1), 67-72. http://dx.doi.org/10.1016/j.placenta.2007.11.001

Belles, M., Linares, V., Perello, G., \& Domingo, J. L. (2013). Human dietary exposure to uranium in Catalonia, Spain. Biol. Trace Elem. Res., 152(1), 1-8. http://dx.doi.org/10.1007/s12011-012-9587-2

Bischoff, K., Higgins, W., Thompson, B., \& Ebel, J. G. (2014). Lead excretion in milk of accidentally exposed dairy cattle. Food Addit Contam Part A Chem Anal Control Expo Risk Assess., 31(5), 839-844. http://dx.doi.org/10.1080/19440049.2014.888787

Cheeke, P. R. (1995). Endogenous toxins and mycotoxins in forage grasses and their effects on livestock. Journal of Animal Science, 73, 909-918. Retrieved from http://www.ncbi.nlm.nih.gov/pubmed/7608026

Cheng, T. H., Lin, J. W., Chao, H. H., Chen, Y. L., Chen, C. H., Chan, P., \& Liu, J. C. (2008). Uric acid activates extracellular signal-regulated kinases and thereafter endothelin-1 expression in rat cardiac fibroblasts. Int. J. Cardiol., 139(1), 42-49. http://dx.doi.org/10.1016/j.ijcard.2008.09.004

Das, A., Bhattacharya, S., Palaniswamy, M., \& Angayarkanni, J. (2014). Biodegradation of aflatoxin B1 in contaminated rice straw by Pleurotus ostreatus MTCC 142 and Pleurotus ostreatus GHBBF10 in the presence of metal salts and surfactants. World $J$ Microbiol Biotechnol., 30(8), 2315-2324. http://dx.doi.org/10.1007/s11274-014-1657-5

Dincer, E. H., Dincer, A. P., \& Levinson, D. J. (2002). Asymptomatic hyperuricemia: To treat or not to treat. Cleve Clin J Med, 69(8), 594-608. http://dx.doi.org/10.3949/ccjm.69.8.594

Elliott, R. B., Harris, D. P., Hill, J. P., Bibby, N. J., \& Wasmuth, H. E. (1999). Type 1(insulin-dependent) diabetes mellitus and cow milk: Casein variant consumption. Diabetologia, 42, 292-296. http://dx.doi.org/10.1007/s001250051153

Feig, D. I., Kang, D. H., \& Johnson, R. J. (2008). Uric acid and cardiovascular risk. N. Engl. J. Med., 359, 1811-1821. http://dx.doi.org/10.1056/NEJMra0800885

Ferreiro, T., Gayoso, L., \& Rodríguez-Otero, J. L. (2015). Milk phospholipids: Organic milk and milk rich in conjugated linoleic acid compared with conventional milk. J. Dairy Sci., 98(1), 9-14. http://dx.doi.org/10.3168/jds.2014-8244 
Fink-Gremmels, J. (2008). Mycotoxins in cattle feeds and carry-over to dairy milk: a review. Food Addit Contam Part A Chem Anal Control Expo Risk Assess., 25(2), 172-180. http://dx.doi.org/10.1080/02652030701823142

Foell, D., Wittkowski, H., \& Roth, J. (2007). Mechanisms of disease: A 'DAMP' view of inflammatory arthritis. Nat .Clin. Pract. Rheumatol., 3(7), 382-390. http://dx.doi.org/10.1038/ncprheum0531

Gonzalez, D., Marquina, R., Rondon, N., Antonio, J., Rodriguez-Malaver, A., \& Reyes, R. (2008). Effects of aerobic exercise on uric acid, total antioxidant activity, oxidative stress and nitric oxide in human saliva. Research in Sports Medicine, 16(2), 128-137. http://dx.doi.org/10.1080/15438620802103700

Harju, M. (2007). Chromatographic separation of lactose and its applications in the dairy industry IDF Symposium Lactose \& its Derivatives. Moscow, Valio Ltd. Retrieved May 14-16, 2007, from http://lactose.ru/present/7Matti_Harju.pdf

Harrison, R. (2002). Milk Xanthine Oxidase: Hazard or Benefit? J. Nutritional \& Environmental Medicine, 12(3), 231-238.

Harrison, R. (2006). Milk xanthine oxidase: Properties and physiological roles. Int. Dairy J. 16, 546-554. http://dx.doi.org/10.1016/j.idairyj.2005.08.016

Iseki, K., Ikemiya, Y., Inoue, T., Iseki, C., Kinjo, K., \& Takishita, S. (2004). Significance of hyperuricemia as a risk factor for developing ESRD in a screened cohort. Am. J. Kidney Dis., 44, 642-650. http://dx.doi.org/10.1053/j.ajkd.2004.06.006

Khaniki, G. R. J. (2007). Chemical contaminants of human milk and public health concerns: A review. Internat. J. Dairy Sci., 2(2), 104-115. http://dx.doi.org/10.3923/ijds.2007.104.115

Kiermeier, F. (1973). Aflatoxin residues in fluid milk. Pure Appl. Chem., 35, 271-274. http://dx.doi.org/10.1351/pac197335030271

Kocic, G., Pavlovic, R., Nikolic, G., Veljkovic, A., Panseri, S., Chiesa, L. M., ... Nikolic, R. (2014). Effect of commercial or depurinized milk on rat liver growth-regulatory kinases, nuclear factor-kappa $\mathrm{B}$, and endonuclease in experimental hyperuricemia: Comparison with allopurinol therapy. J. Dairy Sci., 97, 4029-4042. http://dx.doi.org/10.3168/jds.2013-7416

Kocic, G., Sokolovic, D., Jevtovic, T., Cvetkovic, T., Veljkovic, A., Kocic, H., ... Zivkovic, P. (2014). Short communication: Effect of commercial or depurinized milk diet on plasma advanced oxidation protein products, cardiovascular markers, and bone marrow CD34(+) stem cell potential in rat experimental hyperuricemia. J Dairy Sci, 97, 6823-6827. http://dx.doi.org/10.3168/jds.2014-8556

Kostyra, E., Sienkievicz-Szlapka, E., Jarmolowska, B., Crawczuk, S., \& Kostyra, H. (2004). Opioid peptides derived from milk proteins. Polish J. Food Nutrition Sci., 13(54), 25-35. Retrieved from http://journal.pan.olsztyn.pl/fd.php?f=484

Laugesen, M., \& Elliott, R. (2003). Ischaemic heart disease, Type 1 diabetes, and cow milk A1 beta-casein. N. Z. Med. J., 116(1168), U295.

Markey, O., Vasilopoulou, D., Givens, D. I., \& Lovegrove, J. A. (2014). Dairy and cardiovascular health: Friend or foe? Nutr. Bull., 39(2), 161-171. http://dx.doi.org/10.1111/nbu.12086

Marphy, P. A., Hendrich, S., Landgren, C., \& Bryant, C. M. (2006). Food mycotoxins: an update. J Food Science, 71(5), R51-R65. http://dx.doi.org/10.1111/j.1750-3841.2006.00052.x

Martemucci, G., \& D’Alessandro, A. G. (2013). Progress in nutritional and health profile of milk and dairy products: a novel drug target. Endocr. Metab. Immune Disord. Drug Targets, 13(3), 209-233. http://dx.doi.org/10.2174/18715303113136660045

Mead, M. N. (2007). Nutrigenomics: The Genome-Food Interface. Environ. Health Perspect, 115(12), A582-A589. http://dx.doi.org/10.1289/ehp.115-a582

Meisel, H., \& FitzGerald, R. J. (2000). Opioid peptides encrypted in intact milk protein sequences. British Journal of Nutrition, 83(Suppl. 1), S27-S31. http://dx.doi.org/10.1017/S000711450000221X

Michalski, M. C. (2007). On the supposed influence of milk homogenization on the risk of CVD, diabetes and allergy. Br. J. Nutr., 97, 598-610. http://dx.doi.org/10.1017/S0007114507657900

Miyazaki, H., Tsuchiyama, T., \& Terada, H. (2013). Examination of radioactive contamination in foods. Shokuhin Eiseigaku Zasshi, 54(2), 156-64. http://dx.doi.org/10.3358/shokueishi.54.156 
Nawaz, S., Scudamore, K. A., \& Rainbird, S. C. (1997). Mycotoxins in ingredients of animal feeding stuffs: I. Determination of Alternaria mycotoxins in oilseed rape meal and sunflower seed meal. Food Additives and Contaminants, 14, 249-262. http://dx.doi.org/10.1080/02652039709374522

Nyman, A. K., Ekman, T., Emanuelson, U., Gustafsson, A. H., Holtenius, K., Waller, K. P., \& Sandgren, C. H. (2007). Risk factors associated with the incidence of veterinary-treated clinical mastitis in Swedish dairy herds with a high milk yield and a low prevalence of subclinical mastitis. Preventive Veterinary Medicine, 78, 142-160. http://dx.doi.org/10.1016/j.prevetmed.2006.10.002

Parodi, P. W. (2004). Milk fat in human nutrition. Austral. J. Dairy Technol., 59(1), 3-59. Retrieved from ftp://s173-183-201-52.ab.hsia.telus.net/Inetpub

Qin, L. Q., Xu, J. Y., Han, S. F., Zhang, Z. L., Zhao, Y. Y., \& Szeto, I. M. (2015). Dairy consumption and risk of cardiovascular disease: an updated meta-analysis of prospective cohort studies. Asia Pac J Clin Nutr, 24(1), 90-100. http://dx.doi.org/10.6133/apjen.2015.24.1.09

Salminen, S., Nybom, S., Meriluoto, J., Collado, M. C., Vesterlund, S., \& El-Nezami, H. (2010). Interaction of probiotics and pathogens - Benefits to human health? Curr Opin Biotechnol, 21(2), 157-67. http://dx.doi.org/10.1016/j.copbio.2010.03.016

Schretlen, D. J., Inscore, A. B., Jinnah, H. A., Rao, V., Gordon, B., \& Pearlson, G. D. (2007). Serum uric acid and cognitive function in community-dwelling older adults. Neuropsychology, 21, 136-140. http://dx.doi.org/10.1037/0894-4105.21.1.136

Sculley, D. G., Dawson, P. A., Emmerson, B. T., \& Gordon, R. B. (1992). A review of the molecular basis of hypoxanthine guanine phosphoribosyl transferase (HGPRT) deficiency. Human Genet., 90, 195-207. http://dx.doi.org/10.1007/BF00220062

Segall, J. J. (1994). Dietary lactose as a possible risk factor for ischaemic heart disease: Review of epidemiology. Int. J. Cardiol., 46, 197-207. http://dx.doi.org/10.1016/0167-5273(94)90242-9

Segall, J. J. (2002). Plausibility of Dietary Lactose as a Coronary Risk Factor. Journal of Nutritional \& Environmental Medicine, 12(3), 217-229. http://dx.doi.org/10.1080/1359084021000006885

Simopoulos, A. P. (2010). Nutrigenetics/Nutrigenomics. Ann. Rev. Public Health, 31, 53-68. http://dx.doi.org/10.1146/annurev.publhealth.031809

Sorensen, L. K. (2006). Determination of phthalates in milk and milk products by liquid chromatography/tandem mass spectrometry. Rapid Commun. Mass Spectrom., 20, 1135-1143. http://dx.doi.org/10.1016/j.chroma.2013.11.017

Stevens, C. R., Millar, T. M., Kanczler, J. M., Bodamyali, T., \& Blake, D. R. (2000). Antibacterial properties of

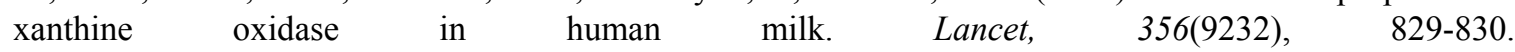
http://dx.doi.org/10.1016/S0140-6736(00)02660-X

Tatli, E., Aktoz, M., Buyuklu, M., \& Altun, A. (2008). The relationship between coronary artery disease and uric acid levels in young patients with acute myocardial infarction. Cardiol. J., 15, 21-25. Retrieved from http://www.ncbi.nlm.nih.gov/pubmed/18651381

Villarroel, A., \& Halliburton, M. K. (2013). Control of extensive chorioptic mange natural infection in lactating dairy cattle without milk withdrawal. Vet J., 197(2), 233-237. http://dx.doi.org/10.1016/j.tvj1.2013.01.003

Warensjo, E., Jansson, J. H., Cederholm, T., Boman, K., Eliasson, M., Hallmans, G., \& Sjogren, P. (2010). Biomarkers of milk fat and the risk of myocardial infarction in men and women: A prospective, matched case-control study. Am. J. Clin. Nutr., 92, 194-202. http://dx.doi.org/10.3945/ajcn.2009.29054

Witczak, A., Mituniewicz-Małek, A., \& Dmytrow, I. (2013). Assessment of daily intake of organochlorine pesticides from milk in different regions of Poland. $J$ Environ Sci Health B, 48(2), 83-91. http://dx.doi.org/10.1080/03601234.2013.726589

Zhou, X. W., \& Zhao, X. H. (2015). Susceptibility of nine organophosphorus pesticides in skimmed milk towards inoculated lactic acid bacteria and yogurt starters. $J$ Sci Food Agric, 95(2), 260-266. http://dx.doi.org/10.1002/jsfa.6710 


\section{Copyrights}

Copyright for this article is retained by the author(s), with first publication rights granted to the journal.

This is an open-access article distributed under the terms and conditions of the Creative Commons Attribution license (http://creativecommons.org/licenses/by/3.0/). 